\title{
Convergência contábil e rentabilidade de fundos de investimentos em ações
}

\author{
Accounting convergence and profitability of brazilian mutual funds
}

La convergencia contable y la rentabilidad de los fondos brasileños de inversión

\section{Kamyr Gomes de Souza}

Mestra em Ciências Contábeis pela Universidade Federal de Uberlândia

Assistente em Administração - Universidade Federal de Uberlândia

Endereço: Rua Vinte, Bairro Tupã

CEP: 38.304-402 - Ituiutaba/MG - Brasil

E-mail:kamyr@ufu.br

Telefone: (34) 3271-5228

\section{Rodrigo Fernandes Malaquias}

Doutor em Administração pela EAESP/FGV

Professor-Adjunto da Universidade Federal de Uberlândia

Endereço: Av. João Naves de Ávila, n. 2121, Bloco F, Sala 1F-215

CEP: 38.400-902 - Uberlândia/MG - Brasil

E-mail: rodrigofmalaquias@ufu.br

Telefone: (34) 3239-4176

Ilírio José Rech

Doutor em Contabilidade e Controladoria pela FEA/USP

Professor-Adjunto da Universidade Federal de Goiás

Endereço: R. Samambaia, s/n - Campus Samambaia

CEP: 74.001-970 - Goiânia/GO - Brasil

E-mail: ilirio@usp.br

Telefone: (62) 3521-1390

Mayane Jacqueline Gonçalves de Melo

Especialista em Finanças e Controladoria Corporativa pela UNIGAP

Coordenadora do curso de Pós-Graduação - PUC-MINAS, Perícia Judicial, Grafotécnica e

Documentoscopia

Endereço: Rua Alagoas, 573, Bairro Brasil

CEP: 38.400-666 - Uberlândia/MG - Brasil

E-mail: mayanejac@yahoo.com.br

Telefone: (34) 3212-2662

Artigo recebido em 01/11/2015. Revisado por pares em 12/09/2017. Reformulado em 24/10/2017. Recomendado para publicação em 08/03/2018 por Carlos Eduardo Facin Lavarda (Editor-Chefe). Publicado em 28/03/2018. 


\title{
Resumo
}

Os fundos de investimento têm se tornado uma opção acessível e com expressiva participação no mercado financeiro, até mesmo para pequenos investidores. A literatura aponta alguns fatores que afetam sua rentabilidade, geralmente relacionados à estrutura do fundo e ao portfólio escolhido pelos gestores. Além disso, as recentes alterações nos padrões contábeis brasileiros podem ter também afetado a rentabilidade dos fundos, a partir da postulada melhoria na qualidade da informação e consequente redução na assimetria informacional. Neste contexto, o objetivo do presente estudo foi analisar a relação entre a adoção das IFRS pelas empresas abertas e a rentabilidade dos fundos de ações brasileiros. Trata-se de uma pesquisa descritiva com abordagem quantitativa, realizada por meio de uma pesquisa documental. Utilizou-se uma amostra de fundos de investimento em ações do tipo Sustentabilidade/Governança e de 27 empresas de capital aberto, das quais 9 realizaram a adoção voluntária ao padrão contábil internacional no ano de 2008 . O período analisado foi de Janeiro de 2007 a Setembro de 2013. Os resultados da pesquisa não se mostraram alinhados às hipóteses iniciais, pois houve maior correlação da rentabilidade dos fundos com a rentabilidade das ações das empresas antes da adoção obrigatória, ou seja, quando elas não adotavam as normas IFRS.

Palavras-chave: IFRS; Fundos de investimento; Rentabilidade

\begin{abstract}
Mutual funds have become an accessible and meaningful participation in the financial market, even by small investor's option. The literature points to several factors that affect its profitability, often related to the structure of the fund and the portfolio chosen by managers. Moreover, recent changes in Brazilian accounting standards may have also affected the profitability of the funds from the postulated improvement in the quality of information and consequent reduction in information asymmetry. The aim of this study was to analyze the influence of adopting IFRS by Brazilian companies on the profitability of Brazilian investment funds. This is a descriptive research with quantitative approach, carried out through a documental research. We used a sample of mutual funds in the category of Sustainability/Governance and 27 listed companies, of which 9 underwent voluntary compliance to international accounting standards in 2008. The period was from January 2007 to September 2013. The main results contradict the initial assumption, because there was a higher correlation of the fund's returns with the company's returns before the mandatory adoption, when they did not adopt IFRS.
\end{abstract}

Keywords: IFRS; Investment funds; Profitability

\section{Resumen}

Los fondos de inversión se han convertido en una opción asequible y con una importante participación en el mercado financiero de Brasil, incluso para los pequeños inversores. La literatura menciona diversos factores que afectan su rentabilidad, generalmente de la estructura del fondo y de la cartera elegida por los gestores. Los recientes cambios en las normas contables brasileñas también pueden haber afectado a la rentabilidad de los fondos con la mejora en la calidad de la información contable y la consiguiente reducción de la asimetría informativa. En este contexto, el objetivo de este estudio fue analizar la influencia de la adopción de las IFRS en la rentabilidad de los fondos de inversión brasileños. Se trata de una investigación descriptiva con un abordaje cuantitativo, realizado a través de la investigación documental. Se utilizó una muestra de los fondos de inversión en acciones de tipo Sostenibilidad / Gobernanza y 27 sociedades cotizadas, de las cuales nueve hicieron la adopción voluntaria de normas internacionales de contabilidad en 2008. El periodo de estudio fue de enero de 2007 y septiembre 2013. Los resultados de la encuesta no estaban 
alineados con las hipótesis iniciales, porque había una mayor correlación entre el rendimiento de los activos y la rentabilidad de los activos de la compañía de la acción antes de la adopción obligatoria, es decir, cuando no se adoptan las IFRS.

Palabras clave: IFRS; Fondos de Inversión; Rentabilidad

\section{Introdução}

Dentre as diversas formas de aplicação disponíveis para poupadores alocarem seus investimentos, vem ganhando destaque os fundos de investimento, cuja procura cresceu significativamente nos últimos anos. Segundo Camilo (2012), aproximadamente dois trilhões de reais estavam aplicados em fundos de investimentos em 2012 no cenário brasileiro, sendo um décimo desse valor investido em fundos de ações. Como um dos motivos para tal crescimento, pode-se apontar a própria revitalização do mercado de ações, que estimulou o aumento da demanda por esse setor e a consequente abertura de fundos de investimento em ações (CAMILO, 2012).

Com isso os gestores dos fundos de investimentos intensificaram sua posição de usuários externos da informação contábil, uma vez que necessitam das demonstrações financeiras de suas investidas para o processo de decisão de investimento e alocação de recursos financeiros. Dessa forma, entende-se que os fundos de investimentos em ações também foram afetados/beneficiados com o processo de convergência às International Financial Reporting Standards (IFRS), aumentando a possibilidade de os mesmos ter acesso a informações de maior qualidade e relevância.

No período pós convergência diversos estudos abordam a melhoria da qualidade e relevância da informação contábil a partir da adoção das IFRS. O estudo de Lima (2011, p. 187) indica que "a relevância da informação contábil mensurada através dos modelos de preço e retorno, aumentou após a adoção parcial das normas IFRS no Brasil". Ainda segundo o autor, isso se justifica tendo em vista que "os mesmos eventos econômicos, quando mensurados por diferentes normas contábeis, alteram as expectativas dos investidores acerca dos lucros futuros da empresa, consequentemente, modificando os preços".

Os benefícios da convergência foram confirmados por Greco et al. (2013, p. 123) do ponto de vista dos profissionais brasileiros. De acordo com a pesquisa, é perceptível que houve avanços do mercado de capitais, devido à melhoria na credibilidade nas informações contábeis e consequente incremento de investimentos estrangeiros na bolsa de valores. Segundo os dados da pesquisa, esse incremento também tem origem nos investidores institucionais, como os fundos de investimento e de pensão, que passaram a ver o mercado brasileiro com menor risco em função do novo ambiente contábil.

Do ponto de vista das empresas abertas, estudos de Silva (2013), Lopes e Alencar (2010), Daske et al. (2008), verificaram que há associação entre a redução de custo de capital e a qualidade da informação contábil. No mesmo sentido Armstrong et al. (2010), em pesquisa realizada na Europa, verificaram uma reação positiva dos investidores a partir de um melhor nível de uniformidade e comparabilidade nos demonstrativos financeiros publicados.

$\mathrm{Na}$ indústria de fundos de investimentos, a literatura na área aponta alguns fatores que afetam a rentabilidade dos fundos. Entre eles destaca-se o tamanho do fundo, o estilo de investimento, as taxas de administração e de performance, a experiência do gestor, a inserção de períodos de crise financeira, e até mesmo a situação de ser um fundo que investe em outros fundos (LHABITANT, 2001; AMIN; KAT, 2003; GROMB; VAYANOS, 2002; JENSEN; MECKLING, 2008; LI; ZHANG; ZHAO, 2008; BODIE; KANE; MARCUS, 2010; MALAQUIAS; EID JR., 2013).

Considerando que os fundos de investimentos, apesar de serem investidores qualificados, também são usuários e necessitam de informações contábeis, supõe-se que o 
processo de convergência tenha afetado a sua rentabilidade, principalmente considerando-se que informações com maior qualidade tendem a melhorar o processo de seleção do portfólio. O conteúdo informacional presente nas demonstrações contábeis é incorporado aos preços (LIMA, 2010) e, consequentemente, aos retornos das ações e dos fundos que nelas investem.

Nesse sentido tem-se a seguinte questão de pesquisa para esse estudo: Qual a relação entre aa adoção das IFRS pelas companhias abertas e a rentabilidade dos fundos brasileiros de investimento em ações? Desta forma, esta pesquisa tem como objetivo analisar a relação entre a adoção das IFRS pelas companhias abertas e a rentabilidade dos fundos brasileiros de investimentos em ações. O fator que permitiu uma estimativa do impacto das IFRS na rentabilidade dos fundos foi a adoção voluntária das IFRS, em que algumas empresas abertas adotaram estas normas mesmo antes de sua obrigatoriedade. Tornou-se possível, então, verificar o nível de atenção dado pelos gestores de fundos de investimentos a estas empresas que, em tese, tenderiam a ser mais transparentes e oferecer informações com maior qualidade.

Para responder ao problema de pesquisa e alcançar o objetivo geral proposto, foram elaboradas as seguintes hipóteses de pesquisa:

H1: A rentabilidade dos fundos de investimento apresentou maior relação com a rentabilidade das ações das empresas que fizeram a adoção voluntária às normas IFRS, em comparação com aquelas empresas que não fizeram a adoção voluntária das IFRS.

H2: A rentabilidade dos fundos de investimento apresentou maior relação com a rentabilidade das ações das empresas em geral, após a adoção das normas IFRS.

Para testar estas hipóteses foram selecionados 11 fundos de investimentos em ações do tipo sustentabilidade e governança e 27 empresas abertas. As empresas foram segregadas entre as que fizeram adoção voluntária (9) e as que atenderam às normas internacionais apenas dentro do período limite recomendado. Para comparar a rentabilidade dos fundos pré e pós adoção, foram selecionados os dados no período de janeiro de 2007 a setembro de 2013, tanto da rentabilidade dos fundos quanto do retorno das ações das empresas. De maneira geral, os resultados indicaram que a adoção voluntária, por si só e na forma de mensuração adotada neste estudo, não representou o principal fator para auxiliar na compreensão das decisões de seleção de ativos tomadas pelos fundos da amostra.

A originalidade e relevância do presente estudo residem na análise da relação entre a convergência contábil e a rentabilidade dos fundos de investimento. Nesse sentido, a pesquisa se propõe, por meio da análise crítica, lançar luz sobre o tema, de grande relevância para o mercado de capitais. Considerando a importância para a área investigada, este se justifica tendo em vista as distintas características do mercado de capitais brasileiro e a importância do conhecimento acerca dos impactos produzidos pela convergência contábil às normas internacionais.

A contribuição deste estudo para a academia consiste no aprofundamento das pesquisas sobre os impactos da adoção das IFRS com ênfase em áreas ainda não exploradas. No que se refere à importância dessa pesquisa para o mercado e para a prática, ressalta-se a possibilidade de melhorar a performance e a rentabilidade dos fundos de investimento por meio de uma melhor seleção do portfólio, até mesmo para auxiliar o investidor individual na escolha de um fundo para investir.

Estruturalmente, este estudo encontra-se dividido em cinco seções, incluindo esta introdução. Na seção seguinte, apresenta-se o referencial teórico, que aborda definições mais amplas sobre fundos de investimentos, processo de alocação de ativos e convergência contábil. A terceira seção apresenta os critérios utilizados para composição da amostra e procedimentos quantitativos de análise dos dados, de forma a se cumprir com o objetivo geral. A quarta seção contém os resultados do estudo e na última seção são apresentadas as considerações finais e sugestões de pesquisas futuras. 


\section{Referencial Teórico}

\subsection{Estrutura e composição dos fundos de investimento}

Os fundos de investimento têm se tornado uma alternativa viável para pequenos e grandes investidores. Mesmo os que dispõem de pequena quantia de capital podem ter acesso à boas opções de investimentos no mercado a um baixo custo (FONSECA et al., 2007).

Ranciaro Neto (2012) ressalta que os fundos de investimento possibilitam a redução da exposição ao risco de seus investidores, por meio da diversificação de seus investimentos. E, posto que a construção de um portfólio ótimo requer considerável conhecimento técnico para seu gerenciamento, os investidores individuais ainda contraem diversos encargos, os quais poderiam ser rateados por meio da aplicação nos fundos de investimento.

Além disso, conforme Fonseca et al. (2007), as alternativas de fundos disponíveis possibilitam a diversificação dos investimentos, reduzindo significativamente $\mathrm{o}$ risco sistemático e aumentando o potencial de retorno do investidor. Por oferecerem uma gestão técnica de carteiras, são capazes de proporcionar maior liquidez, acesso a ativos diversos a um menor custo nas transações permitindo ao investidor melhor planejamento de suas finanças.

No Brasil, a estrutura e funcionamento dos fundos de investimentos são disciplinados pela Instrução 555/14 da Comissão de Valores Mobiliários (CVM). De acordo com a Instrução um fundo investimento é definido como "uma comunhão de recursos, constituída sob a forma de condomínio, destinado à aplicação em ativos financeiros" (CVM, 2014).

Os fundos de investimento foram divididos em diferentes classes, como: Fundos de Renda Fixa, Fundos de Ações, Fundos Cambiais, Fundos Multimercados, além dos Fundos de Investimentos em Cotas (CVM, 2014). Esta subdivisão considerou a composição de suas carteiras, oferecendo ao investidor uma visão mais uniforme acerca dos tipos de fundos de investimento disponíveis no mercado.

Para esse estudo, optou-se pelos fundos de investimentos em ações por estes apresentarem maior proximidade com o mercado de ações e necessidade das demonstrações financeiras; com isso, em tese, estes seriam os fundos mais afetados pela convergência contábil. Os fundos de ações investem no mínimo $67 \%$ de seu patrimônio em ações negociadas em bolsa, sendo que a composição dos 33\% residuais poderá ser aplicada em quaisquer outras modalidades de ativos financeiros (CVM, 2014). Dessa forma, os fundos de ações estão sujeitos às oscilações de preços das ações que compõem sua carteira.

Nota-se que os fundos de investimento comportam diversas modalidades e alternativas para composição de suas carteiras, direcionadas para diferentes níveis de risco e expectativa de retorno. Esse risco pode ser diversificado pela modalidade dos ativos financeiros bem como pela seleção de ativos com maior confiabilidade e qualidade das demonstrações financeiras disponibilizadas. Contudo a seleção dos ativos está relacionada com a teoria do portfólio de Markowitz, explorada com maiores detalhes no próximo subtópico.

\subsection{Teoria do Portfólio e decisões de investimento}

Os investidores, de modo geral, vivem o dilema de aumentarem o risco de suas carteiras na expectativa de obterem maiores retornos, mas, com isso, estão sujeitos a maiores perdas, o que é conhecido como relação risco versus retorno. Desse modo, os investidores racionais terão como requisito que o capital investido "seja remunerado de forma condizente com o risco assumido ao investir em determinado ativo" (FONSECA et al., 2007, p. 97).

No contexto das decisões de investimento, o quesito da assimetria informacional aumenta a exposição dos investidores a riscos desconhecidos. Investidores não detentores de 
informação privilegiada podem ser surpreendidos com riscos que não estavam dispostos a assumir se tivessem acesso a toda informação.

Como forma de mitigar esse risco, Markowitz criou a Teoria dos Portfólios. Fonseca et al. (2007) afirmam que essa teoria parte de um modelo matemático e estatístico para a racionalização da tomada de decisão. Com base no modelo o investidor pode obter melhores retornos com o mesmo nível de risco, considerando a análise do risco não sistemático e sua diversificação.

Conforme Assaf Neto (2010), o risco de um investimento no mercado de capitais subdivide-se em dois grandes grupos, o risco sistemático e o não sistemático. $\mathrm{O}$ risco não sistemático (também chamado de risco diversificável) pode ser mitigado por meio da diversificação da carteira, uma vez que este está relacionado com as características do título e ao risco próprio da empresa emissora do título. Já o risco sistemático não pode ser gerenciado mediante diversificação, uma vez que representa o risco de mercado, originário das flutuações a que o sistema econômico como um todo está sujeito.

De acordo com Varga (2001, p. 237), quando o investidor possui diversos fundos, o risco não-sistemático pode tornar-se desprezível, "já que vários fundos juntos geram uma diversificação suficiente para eliminar esse componente do risco". Porém, Assaf Neto (2010) afirma que essa lógica só se sustenta se os retornos dos ativos não forem positivamente correlacionados entre si. Caso contrário, a correlação positiva entre os títulos invalidaria os efeitos da diversificação. Para que efetivamente a diversificação reduza o risco não sistemático, deve-se evitar ativos com alta correlação positiva entre si.

Pela análise da Teoria dos Portfólios, pode-se verificar que, teoricamente, ela minimiza a exposição ao risco proporcionado pela assimetria informacional. Como afirma Assaf Neto (2010, p. 201), "o processo de diversificação do risco é uma medida estratégica indispensável de ser adotada em ambientes sob condições de incerteza". Contudo, se o fundo tem acesso a ativos com maior volume de informações, seu gestor pode selecionar um portfólio entre os melhores, podendo mitigar o risco não sistemático e melhorar o seu retorno, com menor exposição a surpresas que podem ser evitadas.

De acordo com a filosofia da convergência, as empresas passariam a apresentar informações mais confiáveis, o que resulta na melhoria das opções de portfólio disponíveis aos fundos de investimentos, no papel de investidores institucionais. Consequentemente, pode ocorrer uma melhora na rentabilidade destes e alocação dos recursos em empresas rentáveis e comprometidas com a qualidade da informação. Com isso têm-se um círculo parcimonioso entre investidores e investidas, especialmente para investidas que apresentam maior preocupação em evidenciar informações de maior qualidade.

Desta forma, os fundos podem melhorar a alocação de seus recursos, obedecendo o perfil do fundo ou de seus cotistas, com redução dos riscos provocados pela assimetria informacional. Assim seria mais rentável aquele fundo de investimentos que consegue tomar decisões baseadas em estratégias adequadas com uma gestão mais eficaz.

Conforme Varga (2001), o processo de seleção de um fundo de investimento pode ser feito em duas etapas. Na primeira, verifica-se qual a carteira mais adequada para o perfil do investidor e, na segunda, procura-se um gestor que possa superar o mercado. Mas, para superar o mercado, o gestor precisa ter acesso às melhores informações, e/ou possuir modelos capazes de melhor processar um volume maior de informações disponíveis. Dessa forma, "é o conjunto de informação e/ou seus modelos que permitem ao bom gestor proporcionar um retorno superior ao do mercado, justificando assim a administração ativa" (VARGA, 2001, p. 216). Desta forma, depreende-se que mesmo diante do trade-off risco e retorno no processo de alocação de recursos, a assimetria informacional tem uma participação relevante e informações mais detalhadas podem contribuir com a menor volatilidade dos retornos dos fundos. 
De acordo com Varga (2001), existem alguns indicadores para avaliação de performance, como o índice de Sharpe, que auxilia os investidores em sua tomada de decisão - desde que, em sua utilização, estimem-se corretamente seus parâmetros e a aplicação pretendida. Porém, apesar de estes indicadores estimarem razoavelmente bem a relação de risco e retorno, não são capazes de indicar quesitos relacionados à informação. Assim os gestores detentores de informação privilegiada apresentariam propensão para alterar suas carteiras em função da maior quantidade de informação, gerando elevada volatilidade. Em situação oposta, se um fundo possui uma carteira estática, depreende-se que seu gestor não tenha informação ou modelos superiores (ADMATI; ROSS, 1985) para desenvolver a gestão ativa.

Segundo Admati e Ross (1985), um desempenho superior na gestão de carteiras pode estar ligado a posse de informações superiores, de forma que os gestores poderiam, assim, alterarem a composição de sua carteira. A posse de informações superiores pode resultar de um melhor aporte tecnológico ou da própria qualificação da equipe do gestor, o que lhe conferiria maior capacidade para absorver e processar as informações disponíveis.

Sob esta perspectiva, o processo de convergência internacional tem um papel significativo na melhora níveis de evidenciação e qualidade da informação disponibilizada a seus usuários. Pois, se a convergência ao modelo IFRS implica em melhores informações, o nível de assimetria informacional entre investidores e empresas poderiam ser minimizadas, ressaltando o papel da contabilidade para a alocação eficiente de recursos no mercado financeiro (LIMA, 2010). Assim, faz-se importante mencionar uma breve análise do processo de convergência no Brasil e os efeitos identificados nas pesquisas sobre a qualidade da informação contábil, proporcionado pela adesão às normas IFRS.

\subsection{Processo de Convergência e seus efeitos na informação Contábil}

O ambiente de globalização de mercados da economia mundial foi um dos grandes motivadores para a criação das normas internacionais de contabilidade que atendessem aos diferentes usuários da informação financeira, já que estes necessitavam de uma linguagem universal para os negócios, especialmente para redigirem e compreenderem os relatórios financeiros de diferentes regiões do mundo. Pesquisas anteriores, realizadas em diferentes países, indicam que o processo de convergência contábil tem ocorrido de forma gradual e substancial (RIBEIRO et al, 2013).

Especificamente no Brasil, os primeiros avanços contábeis em convergência com as IFRS foram dados em 2005, com as resoluções 488 e 489 da CVM. Estas já prescreviam conceitos das normas internacionais, apesar de não as mencionar em seu bojo. Posteriormente, a Instrução CVM n ${ }^{\circ}$ 457/07 exigiu que as companhias abertas apresentassem, a partir do exercício findo em 2010, suas demonstrações financeiras consolidadas de acordo com o padrão contábil internacional, emitido pelo International Accounting Standards Board - IASB.

De acordo com a Instrução 457/07, havia a necessidade de que as práticas contábeis brasileiras serem convergentes com as práticas contábeis internacionais em função do aumento da transparência e da confiabilidade nas informações financeiras como forma de possibilitar o acesso das empresas nacionais às fontes de financiamento externas a um custo mais acessível.

Apesar de suas origens legalistas e de sua histórica conformidade entre os sistemas contábeis e fiscais, o Brasil obteve significativo avanço na qualidade de suas informações financeiras após a aprovação da Lei n. 11.638/07 e da edição dos pronunciamentos técnicos pelo CPC. Em 2010, o Comitê de pronunciamentos Contábeis (CPC), criado ainda em 2005, 
já havia publicado todas as normas de contabilidade brasileiras que substituem, para as empresas brasileiras, as IAS/IFRS.

Com a edição da lei, o processo de convergência passou a caminhar de modo mais acelerado. Silva (2010, p. 71) observa que com a promulgação da Lei $n^{\circ} 11.638 / 07$ algumas mudanças já foram respeitadas no balanço anual de 2008. A partir do exercício social de 2008, algumas companhias abertas passaram a utilizar voluntariamente práticas contábeis condizentes com as internacionais mesmo que sua obrigatoriedade se desse somente a partir de 2010.

De acordo com Martins e Paulo (2010), a adoção das IFRS impactou a magnitude dos itens das demonstrações contábeis das companhias e, consequentemente, de seus indicadores de desempenho. Neste sentido, Prado (2013) constatou que a transição para as IFRS trouxe diferenças significativas nos valores das rubricas das empresas, se comparados com o padrão contábil anterior.

Assim, as divergências de apresentação da contabilidade em diversas normas, uma vez que nem todas as empresas adotaram as normas convergidas, e seus indicadores referentes podem ter sérias influências na tomada de decisão. Essa consequência contraria o objetivo da convergência contábil ao padrão internacional de reduzir essas divergências, melhorando o grau de comparabilidade entre os resultados das companhias.

A importância da contabilidade relaciona-se diretamente com sua capacidade de gerar informações que influenciam as expectativas de seus usuários. Essa importância pode ser mensurada pela capacidade de alterar volumes negociados ou preços, na publicação das demonstrações financeiras. Considerando-se a que os mercados sejam eficientes, qualquer informação útil pode influenciá-los, inclusive a contábil, fazendo com que o investidor revise sua expectativa de lucros futuros, riscos e retornos, o que afeta os preços das ações (SCOTT, 2009; SARLO NETO; BASSI; ALMEIDA, 2011).

A Contabilidade também tem um importante papel na redução da assimetria informacional, a qual afeta negativamente o desempenho do mercado. A assimetria informacional entre os administradores de recursos e os investidores, alinhada à teoria da agência, aumenta os custos de transação e reduz a liquidez dos títulos (JENSEN; MECKLING, 2008; REZENDE; ALMEIDA; LEMES, 2012). Nesse quesito, estima-se que a adoção das IFRS apresentou um impacto benéfico, por recomendar e ou exigir a veiculação de informações mais claras e compreensíveis, com capacidade de atender as necessidades dos usuários externos no processo de tomada de decisão.

Pesquisas realizadas com o objetivo de analisar o impacto das informações contábeis produzidas conforme as normas IFRS para o mercado de capitais concluíram que essas melhoram a informatividade das demonstrações financeiras. Adicionalmente, Lima et al. (2010); Silva (2013); Lopes e Alencar (2010); Daske et al. (2008) concluíram que há uma associação inversamente proporcional entre a qualidade da informação divulgada e o custo de capital.

De acordo com Lima et al. (2010), maior divulgação de informações contábeis reduz a estimação de risco dos investidores o proporciona maior facilidade para estimar os fluxos futuros de caixa da firma. Além disso, melhora a segregação de risco alertando os investidores sobre o risco de certas ações. Estes por sua vez são levados a rever suas posições e reposicionar-se perante suas curvas individuais de risco x retorno. Desta forma, mesmo para gestores que buscam otimizar suas carteiras com base na relação de risco e retorno, a informação contábil mostra-se como uma variável relevante para a tomada de decisões.

Carvalho, Silva e Silva (2013) afirmam que a divulgação de notícias boas ou ruins pode influenciar o processo de tomada de decisão. Os autores analisaram o comportamento dos acionistas na decisão entre as opções para comprar, manter ou vender ações, mediante a divulgação da informação contábil. Seus resultados sugerem que, na ausência de informações 
de mercado, os investidores optam por adquirir ações de empresas mais conhecidas. Porém, os investidores tendem a vender ações de empresas alavancadas e comprar ações de empresas com altos índices de rentabilidade. Além disso, verificou-se que empresas com maior evidenciação atraem mais acionistas, sendo que, ao deixar de divulgar informações aos seus acionistas, estes tendem a vender suas ações.

Daske et al. (2008) investigaram o efeito da adoção das IFRS nos mercados de capitais de 26 países e verificaram como consequência a redução do custo de capital, aumento na liquidez e aumento nas avaliações das ações. Contudo, Lima (2010, p. 186) destaca que "as empresas têm incentivos heterogêneos em refletir a sua realidade econômica através das demonstrações contábeis". Por isso, esses incentivos podem mitigar o impacto da convergência para algumas empresas. Segundo o autor em sua pesquisa o mesmo constatou que para empresas que negociam American Depositary Receipt (ADR), "não foram constatadas diferenças em seu conteúdo informacional antes e depois do início do processo de migração para as normas IFRS" (LIMA, 2010, p. 186-187).

Essas pesquisas e as consequências para as decisões de investimentos sugerem que os fundos de investimentos podem ter sido afetados pelo processo de convergência. Se os números contábeis mudaram com a convergência, é possível supor que a rentabilidade dos fundos também tenha sido impactada.

\section{Procedimentos Metodológicos}

A presente pesquisa classifica-se, quanto aos objetivos como descritiva, a qual, de acordo com Cervo e Bervian (1996, p. 49) "observa, registra, analisa e correlaciona fatos ou fenômenos (variáveis) sem manipulá-los". Quanto à abordagem, foi uma pesquisa quantitativa que, segundo Richardson (2011, p. 70), "representa, em princípio, a intenção de garantir a precisão dos resultados, evitar distorções de análise e interpretação, possibilitando, consequentemente, uma margem de segurança quanto às inferências". Para a coleta de dados foi utilizado a metodologia da pesquisa documental. Para Beuren et al. (2009, p. 92) esta "baseia-se em materiais que ainda não receberam um tratamento analítico ou que podem ser reelaborados de acordo com os objetivos da pesquisa".

Para atender ao objetivo da pesquisa, foi necessário comparar a rentabilidade dos fundos de investimento com a rentabilidade das ações de empresas que adotaram/não adotaram voluntariamente as IFRS. Para tanto, foram compostos dois grupos de empresas: Grupo 1, composto por empresas que aderiram voluntariamente às IRFS a partir de 2008; e Grupo 2, com empresas que não fizeram a adoção voluntária no referido ano. Entende-se que pode haver algum viés caso haja empresas que seguiam os requerimentos da IFRS em 2007/2008 e não foram incluídas no Grupo 1, o que pode representar uma limitação desta pesquisa.

Dessa forma, a partir do estudo de Martins e Paulo (2010), identificaram-se 13 empresas que realizaram a adoção voluntária às IFRS a partir do exercício social de 2008. As 13 empresas nessas condições foram: Ambev, Eternit, GOL, Lupatech, Mangels, Positivo, Renner, Romi, Santander, São Carlos, Souza Cruz, TAM e UOL. A partir da identificação das empresas foram obtidas, por meio do Banco de dados Economática, as cotações de fechamento das ações para o período de 2007 a 2013. A escolha do período de 2007 a 2013 justifica-se pela possibilidade de realizar o acompanhamento e verificar a performance da rentabilidade das ações das empresas e dos fundos desde a publicação da Lei 11.638/07 até o presente.

No entanto, quatro das empresas da amostra de adoção voluntária apresentaram missing values para mais de 100 observações de cotações diárias. Desta forma, elas foram 
excluídas da amostra estudada, restando 9 empresas, cada uma com 1.683 retornos diários. Estas 9 empresas compõem o Grupo 1.

Para a escolha das demais empresas - que não realizaram a adoção voluntária - fez-se uma pré-seleção considerando as empresas do mesmo setor econômico das empresas do primeiro grupo e que possuíam dados suficientes para análise no período. Dentre estas empresas, foram selecionadas aquelas com maior Ativo Total, com base nos dados consolidados das empresas em 31/12/2006. Fizeram parte deste grupo as empresas: BRF S.A., M. Dias Branco, Lojas Americanas, Natura, Whirlpool, Itautec, Portobello, Itausa, Bradespar, Souza Cruz, Gerdau Metalúrgica, Gerdau, Sid Nacional, Usiminas, Totvs, All América Latina, CCR S.A. e Arteris. Chegou-se, então, a uma amostra de 18 empresas que não realizaram a adoção voluntária no período indicado, sendo estas empresas as que compõem o Grupo 2. Desta forma, a amostra final totaliza 27 empresas.

No que se refere aos fundos de investimentos, foram selecionados fundos de investimentos em ações, especificamente na categoria Ações Sustentabilidade/Governança, com dados completos para o período analisado. Justifica-se a escolha dessa categoria por serem fundos que investem exclusivamente em empresas com bons níveis de governança corporativa, ou com destaque em responsabilidade social e sustentabilidade empresarial (ANBIMA, 2015). Dessa forma, entende-se que essa categoria de fundos tem, potencialmente, uma propensão maior para valorizar as ações de empresas comprometidas com a transparência de suas demonstrações.

Para o período de 02/01/2007 a 12/09/2013, houve 11 fundos com dados completos em termos de retornos diários. Esta amostra representa 33\% do total de fundos de ações que se encontravam classificados na categoria Ações Sustentabilidade/Governança em 12/09/2013. A rentabilidade dos fundos (retorno simples) foi extraída do Sistema de Informações ANBIMA (SI-ANBIMA).

O tratamento estatístico foi realizado por meio da estatística descritiva para os dados da amostra; análise de médias para os retornos das ações antes e depois da adoção dos padrões contábeis internacionais; e correlação entre os retornos dos fundos e os retornos das ações, antes e depois da adoção das IFRS. Utilizou-se o software Statistical Package for the Social Sciences (SPSS).

\section{Resultados e Discussões}

Para comparar a rentabilidade dos fundos de investimento e a rentabilidade das ações de empresas que adotaram ou não as IFRS, conforme já apontado na metodologia, foram criados dois grupos para a análise. O Grupo 1 foi composto por empresas que adotaram voluntariamente as IFRS antes do ano de 2010; e o Grupo 2, composto por empresas que não adotaram voluntariamente as IFRS.

Inicialmente, para a análise dos fundos, foi estimada a rentabilidade de uma carteira composta pelos 11 fundos, supondo-se quantidade igual investida em cada um deles. A Tabela 1 evidencia os coeficientes de correlação de Spearman entre a rentabilidade de cada um dos 11 fundos da amostra e a rentabilidade da carteira estimada. A título de exemplo, o primeiro coeficiente de correlação apresentado na Tabela 1 (igual a 0,976 ) indica que o fundo de código 94579 apresentou uma correlação positiva e forte com a rentabilidade média da carteira composta pelos 11 fundos da amostra.

Resultados similares aos disponíveis na Tabela 1 foram obtidos quando as séries históricas foram segregadas entre os dois seguintes períodos: 02/01/2007 a 31/12/2009 (adoção voluntária das IFRS); e 01/01/2010 a 12/09/2013 (adoção obrigatória das IFRS). 
Tabela 1: Correlação entre a rentabilidade dos fundos e a rentabilidade da carteira estimada

\begin{tabular}{lcccccc}
\hline Cod. Fundo & $\mathbf{9 4 5 7 9}$ & $\mathbf{9 4 6 8 4}$ & $\mathbf{1 2 4 9 3 1}$ & $\mathbf{1 3 2 1 5 2}$ & $\mathbf{1 3 2 2 1 7}$ & $\mathbf{1 5 2 5 1 1}$ \\
Coef. Correl. & 0.976 & 0.976 & 0.987 & 0.988 & 0.988 & 0.984 \\
Cod. Fundo & $\mathbf{1 5 3 2 1 4}$ & $\mathbf{1 5 3 2 3 0}$ & $\mathbf{1 5 3 2 8 1}$ & $\mathbf{1 7 0 3 9 9}$ & $\mathbf{1 7 0 4 4 5}$ & Média \\
\hline Coef. Correl. & 0.980 & 0.980 & 0.971 & 0.965 & 0.966 & 0.978 \\
\hline
\end{tabular}

Fonte: Dados da pesquisa.

Nota: Na última coluna da segunda linha tem-se a média dos coeficientes de correlação.

Com base nos dados da Tabela 1, optou-se por utilizar na análise quantitativa a rentabilidade da carteira com os 11 fundos para representar os retornos dos fundos de Ações Sustentabilidade/Governança, uma vez que a correlação entre os retornos desta carteira e os retornos de cada um dos fundos se mostrou muito forte, com coeficientes acima de 0,96 em todos os casos. Na Tabela 2, apresenta-se a estatística descritiva para os grupos de empresas e para a carteira estimada dos fundos de investimentos.

Tabela 2: Estatística descritiva para as variáveis da amostra

\begin{tabular}{|c|c|c|c|c|c|c|c|c|}
\hline & Variáveis & Mediana & Amplitude IQ & Média & Desvio Padrão & Mínimo & Máximo & P-valor \\
\hline & Carteira de Fundos & 0.040630 & 1.576737 & 0.039373 & 1.689584 & -10.115123 & 14.585503 & 0.000000 \\
\hline \multirow{9}{*}{ 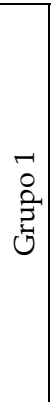 } & Ambev & 0.000494 & 0.018249 & 0.001040 & 0.017884 & -0.139215 & 0.111441 & 0.000005 \\
\hline & Eternit & 0.000000 & 0.019933 & 0.000604 & 0.023534 & -0.425726 & 0.123687 & 0.000000 \\
\hline & Gol & -0.000936 & 0.039221 & -0.001040 & 0.035446 & -0.243600 & 0.217723 & 0.000213 \\
\hline & Lupatech & 0.000000 & 0.032425 & -0.002429 & 0.036042 & -0.298493 & 0.217478 & 0.000000 \\
\hline & Positivo & -0.000207 & 0.030213 & -0.001002 & 0.037587 & -0.304735 & 0.581356 & 0.000000 \\
\hline & Renner & 0.000000 & 0.031894 & 0.000538 & 0.029521 & -0.179837 & 0.192372 & 0.000293 \\
\hline & Souza Cruz & 0.000000 & 0.023530 & 0.000977 & 0.021330 & -0.104557 & 0.124076 & 0.000648 \\
\hline & Tam & 0.000000 & 0.028819 & -0.000504 & 0.032988 & -0.669371 & 0.244079 & 0.000000 \\
\hline & Uol & 0.000000 & 0.020107 & 0.000479 & 0.031560 & -0.669371 & 0.653376 & 0.000000 \\
\hline \multirow{18}{*}{ 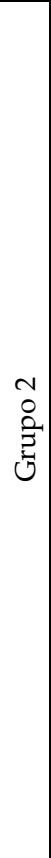 } & BRF SA & 0.000000 & 0.024282 & 0.000841 & 0.023330 & -0.106816 & 0.169060 & 0.000046 \\
\hline & JBS & 0.000000 & 0.037378 & -0.000022 & 0.034052 & -0.254234 & 0.240916 & 0.000431 \\
\hline & Marfrig & 0.000000 & 0.028649 & -0.000533 & 0.031400 & -0.285462 & 0.245122 & 0.000000 \\
\hline & Natura & 0.000000 & 0.025792 & 0.000443 & 0.021948 & -0.147796 & 0.126041 & 0.021875 \\
\hline & Weg & 0.000000 & 0.021435 & 0.000524 & 0.026402 & -0.328504 & 0.328504 & 0.000000 \\
\hline & Sabesp & 0.000000 & 0.027052 & 0.000332 & 0.028601 & -0.199327 & 0.216685 & 0.000000 \\
\hline & Copasa & 0.000000 & 0.020630 & 0.000294 & 0.021482 & -0.174353 & 0.116921 & 0.000000 \\
\hline & Sanepar & 0.000000 & 0.020100 & 0.000714 & 0.022216 & -0.175677 & 0.133531 & 0.000000 \\
\hline & Jereissati & 0.000000 & 0.028392 & 0.000333 & 0.031639 & -0.202941 & 0.393043 & 0.000000 \\
\hline & Localiza & 0.000000 & 0.029565 & 0.000352 & 0.029049 & -0.205984 & 0.240955 & 0.000001 \\
\hline & Gerdau Met & 0.000000 & 0.029450 & 0.000015 & 0.027510 & -0.179868 & 0.139082 & 0.000019 \\
\hline & Gerdau & 0.000000 & 0.029863 & 0.000057 & 0.026830 & -0.136966 & 0.139762 & 0.000364 \\
\hline & Sid Nacional & 0.000000 & 0.030623 & 0.000129 & 0.029603 & -0.187713 & 0.196276 & 0.000005 \\
\hline & Usiminas & 0.000000 & 0.038166 & -0.000349 & 0.033673 & -0.149623 & 0.154565 & 0.011371 \\
\hline & Paranapanema & 0.000000 & 0.030046 & -0.000578 & 0.033209 & -0.168335 & 0.173272 & 0.000000 \\
\hline & Ferbasa & 0.000000 & 0.026317 & 0.000931 & 0.026761 & -0.119059 & 0.144910 & 0.000000 \\
\hline & Totvs & 0.000000 & 0.024679 & 0.000909 & 0.022300 & -0.177996 & 0.127036 & 0.000599 \\
\hline & Telef Brasil & 0.000000 & 0.019339 & 0.000362 & 0.017805 & -0.084995 & 0.081975 & 0.000093 \\
\hline
\end{tabular}

Fonte: Dados da pesquisa

Notas: A última coluna refere-se ao nível de significância para o teste de normalidade Kolmogorov-Smirnov.

Com base no procedimento aplicado aos fundos de investimento, procurou-se estimar uma carteira com a rentabilidade média das empresas do Grupo 1 durante o período. A rentabilidade desta carteira foi então correlacionada com o retorno das ações de cada uma das 
empresas. Contudo, diferentemente do cenário apresentado para o mesmo procedimento aplicado a fundos de investimento (em que todas as correlações foram superiores a 0,96), as estimativas de correlação entre a rentabilidade das ações e a rentabilidade da carteira dos fundos ficaram em torno de 0,54. Assim, optou-se por não utilizar a carteira para representar o comportamento das ações no período, e sim utilizar cada ação individualmente, procedimento também adotado para as empresas do Grupo 2.

A partir da análise da Tabela 2, verifica-se que, ao nível de significância de $5 \%$, nenhum dos grupos apresentou distribuição normal. A amplitude interquartil também foi alta, o que evidencia uma alta volatilidade dos retornos, tanto das ações quanto dos fundos de investimento. Partiu-se, então, para o cálculo da correlação entre os retornos das ações das empresas de cada grupo e o retorno da carteira média dos 11 fundos de investimento, no período de 2007-2013, 2007-2009 e 2010-2013, conforme a Tabela 3.

Tabela 3: Estimativas para os coeficientes de correlação entre os retornos das ações das empresas e o retorno da carteira média dos 11 fundos de investimento

\begin{tabular}{|c|c|c|c|c|c|c|c|}
\hline \multicolumn{4}{|c|}{ Grupo 1} & \multicolumn{4}{|c|}{ Grupo 2} \\
\hline Variáveis & $\begin{array}{c}\text { Periodo } \\
2007-2013\end{array}$ & $\begin{array}{c}\text { Periodo } \\
2007-2009\end{array}$ & $\begin{array}{c}\text { Periodo } \\
2010-2013\end{array}$ & Variáveis & $\begin{array}{c}\text { Periodo } \\
2007-2013\end{array}$ & $\begin{array}{c}\text { Periodo } \\
2007-2009\end{array}$ & $\begin{array}{c}\text { Periodo } \\
2010-2013\end{array}$ \\
\hline Ambev & 0.4369 & 0.4901 & 0.3857 & BRF SA & 0.4947 & 0.4972 & 0.5047 \\
\hline Eternit & 0.3754 & 0.4103 & 0.3454 & M.Diasbranco & 0.3027 & 0.3230 & 0.2918 \\
\hline Gol & 0.4419 & 0.3844 & 0.5154 & Lojas Americ & 0.4529 & 0.4347 & 0.4868 \\
\hline Lupatech & 0.3786 & 0.4254 & 0.3335 & Natura & 0.3747 & 0.3755 & 0.3847 \\
\hline Mangels & 0.2480 & 0.2879 & 0.2062 & Whirlpool & 0.0874 & 0.1152 & 0.0563 \\
\hline Positivo & 0.3939 & 0.3995 & 0.3924 & Itautec & 0.0901 & 0.1140 & 0.0456 \\
\hline Renner & 0.5145 & 0.5249 & 0.5143 & Portobello & 0.1558 & 0.1210 & 0.1902 \\
\hline Romi & 0.2570 & 0.3607 & 0.1543 & Itausa & 0.3254 & 0.3773 & 0.2770 \\
\hline Santander & 0.0213 & 0.0402 & 0.0058 & Bradespar & 0.5656 & 0.6112 & 0.5216 \\
\hline São Carlos & 0.2579 & 0.2949 & 0.2392 & Souza Cruz & 0.4038 & 0.4564 & 0.3557 \\
\hline Souza Cruz & 0.4038 & 0.4564 & 0.3557 & Gerdau Met & 0.6096 & 0.6441 & 0.5821 \\
\hline Tam & 0.4390 & 0.4449 & 0.4491 & Gerdau & 0.7077 & 0.7278 & 0.6970 \\
\hline Uol & 0.3120 & 0.3469 & 0.2812 & Sid Nacional & 0.6895 & 0.7063 & 0.6781 \\
\hline Média* & 0.6596 & 0.6910 & 0.6324 & Usiminas & 0.5704 & 0.6226 & 0.5286 \\
\hline Média** & 0.3446 & 0.3743 & 0.3214 & Totvs & 0.2915 & 0.3356 & 0.2429 \\
\hline & & & & All Amer Lat & 0.3153 & 0.1887 & 0.4489 \\
\hline & & & & CCR SA & 0.4247 & 0.4236 & 0.4394 \\
\hline & & & & Arteris & 0.3752 & 0.4065 & 0.3520 \\
\hline & & & & Média* & 0.8094 & 0.7934 & 0.8398 \\
\hline & & & & Média** $^{* *}$ & 0.4021 & 0.4156 & 0.3935 \\
\hline
\end{tabular}

Fonte: Dados da pesquisa

Notas: Média* - Correlação entre os retornos da carteira de fundos e a média dos retornos das empresas do grupo; Média** - Média das correlações entre os retornos da carteira de fundos e os retornos de cada empresa do grupo.

Por meio da Tabela 3, observa-se que o Grupo 1 apresentou maiores coeficientes de correlação no período no qual a adoção das IFRS era voluntária do que no período em que a adoção das IFRS passou a ser obrigatória $(0,3743$ contra 0,3214$)$. O mesmo fenômeno ocorreu no Grupo 2, que no período no qual houve adoção voluntária das IFRS, apresentou maiores coeficientes de correlação do que no período em que a adoção das IFRS passou a ser obrigatória, mesmo estas empresas não tendo adotado voluntariamente as IFRS. 
Este fato aponta um resultado não necessariamente alinhado à hipótese estabelecida $(\mathrm{H} 2)$, pois houve maior associação entre a rentabilidade dos fundos e das empresas antes da adoção obrigatória, ou seja, quando as empresas do Grupo 2 não adotavam as normas IFRS. Após a adoção obrigatória, houve uma redução da correlação entre as empresas e os fundos de investimento analisados, pois o coeficiente de correlação médio caiu de 0,416 para 0,394. Com isso, a hipótese $\mathrm{H} 2$ não foi suportada, pois além de não se verificar maior associação da rentabilidade dos fundos de investimento com as empresas com as empresas do Grupo 2 quando elas finalmente adotaram o padrão internacional, observou-se uma redução na força desta associação.

Já se confrontando os Grupos 1 e 2, verifica-se que, no período em que a adoção das IFRS foi voluntária, a rentabilidade das empresas que assim o fizeram teve menor associação com a rentabilidade dos fundos do que a daquelas que não optaram voluntariamente pelas IFRS $(0,3743$ contra 0,4156). Verificou-se então, que a hipótese H1 também não foi suportada, pois a rentabilidade dos fundos de investimento apresentou menor associação com as empresas que fizeram a adoção voluntária às normas IFRS, em comparação com as demais.

De modo geral, verifica-se que a maioria das correlações do Grupo 1 são de magnitude moderada a baixa, revelando baixo poder de associação com a carteira de fundos amostrada. Já no Grupo 2, houve maior quantidade de empresas apresentando correlações de média magnitude. No entanto, observa-se que, apesar de as correlações individuais das empresas com a carteira de fundos serem, em média, de baixa magnitude, isso já não ocorre com a correlação entre os retornos da carteira de fundos e a média dos retornos das empresas do Grupo 1 e do Grupo 2, que foram de 0,66 e 0,81, respectivamente. Isso pode ser um indício de que a rentabilidade dos fundos não apresenta um alto poder de associação com as empresas individualmente, mas possui correlações de média/alta magnitude com conjuntos de ações. Esse comportamento mostra-se alinhado à Teoria dos Portfólios, conforme considerações apresentadas no referencial teórico (VARGA, 2001; FONSECA et al., 2007; ASSAF NETO, 2010) desta pesquisa sobre os benefícios da diversificação, com a redução de riscos e potencial aumento do retorno ajustado ao risco, justificando, assim, a gestão ativa.

Outro fator que merece ser considerado é que as empresas que apresentaram correlações de mais alta magnitude com a carteira de fundos são exatamente aquelas que tem se mantido nas carteiras do índice Ibovespa nos últimos anos, a exemplo da Gerdau, com 0,71, Siderúrgica Nacional, com 0,70, Gerdau Metalúrgica, com 0,61, Usiminas, com 0,57, Renner, com 0,51, BRF AS, com 0,50, Lojas Americanas, com 0,45, Ambev, com 0,44, e Souza Cruz, com 0,40. Isso pode indicar que os gestores dos fundos podem priorizar empresas com maior liquidez no momento da composição de suas carteiras. O capital investido pelos cotistas deve ser remunerado de forma condizente com o respectivo nível de risco da carteira dos fundos (FONSECA et al., 2007); assim, o balanceamento ótimo para se poder proporcionar o melhor retorno esperado pode passar por outras variáveis que não necessariamente estejam relacionadas com as informações divulgadas no padrão IFRS.

Adicionalmente, verificou-se que o tamanho médio dos fundos selecionados para a amostra é consideravelmente maior que o tamanho médio dos fundos em Sustentabilidade/Governança, pois as mesmas são de $\mathrm{R} \$ 120,2$ milhões e $\mathrm{R} \$ 68,0$ milhões, respectivamente. Dessa forma, vislumbra-se como uma possível explicação para a baixa aderência dos resultados às hipóteses preestabelecidas o próprio tamanho dos fundos, uma vez que fundos maiores tendem a apresentar melhor performance (LHABITANT, 2001; MALAQUIAS; EID JR., 2013). Considerando que a posse de informações superiores pode motivar as alterações na composição de carteiras (ADMATI; ROSS, 1985), os fundos maiores podem apresentar melhor aporte e capacidade para processar informações superiores do que os fundos menores e, portanto, podem ser menos dependentes da análise fundamentalista. 


\section{Considerações Finais}

A recente literatura acadêmica tem explorado exaustivamente a temática da convergência contábil às IFRS, mas ainda não havia se estudado seu impacto sobre os fundos de investimento. Assim sendo, este artigo teve como objetivo analisar a relação entre a adoção das IFRS e a rentabilidade dos fundos brasileiros de investimentos ou, mais especificamente, nos fundos de investimentos em ações sustentabilidade/governança.

A pressuposição inicial era de que a rentabilidade das ações das empresas que fizeram a adoção voluntária teria maior associação com os fundos de investimento da amostra, observando-se que um dos critérios para seleção das empresas para investimento nestes fundos envolve empresas mais comprometidas com a transparência, por meio de melhores práticas de governança corporativa. Além disso, o fato de a convergência contábil proporcionar melhor qualidade para a informação poderia ser um fator bem-visto pelos gestores de fundos, que buscariam investir nessas empresas que teriam potencial para menor assimetria informacional, minimizando, assim, a volatilidade dos retornos de suas carteiras. Contudo, deve-se considerar também a relação risco e retorno nas decisões de alocação de recursos por parte dos gestores de fundos, o que justificaria em maior parte os investimentos realizados em determinada empresa. Isolando-se o efeito em empresas com o mesmo retorno esperado e o mesmo nível de risco, o quesito transparência poderia ser uma variável com maior poder explicativo em relação ao que foi adotado para a presente pesquisa. Ao mesmo tempo em que esta representa uma limitação deste estudo, também indica oportunidades para novas pesquisas.

Um resultado atípico ocorreu no período de 2007 a 2009, quando a adoção era voluntária, pois as empresas que aderiram às IFRS voluntariamente apresentaram menor associação com os fundos de investimento do que as empresas do segundo grupo. A partir desses resultados, a hipótese $\mathrm{H} 1$ não foi suportada, pois a rentabilidade dos fundos de investimento apresentou menor associação com empresas que fizeram a adoção voluntária as normas IFRS. Além disso, para o grupo de empresas que só realizaram a adoção obrigatória, em 2010, houve maior associação entre as rentabilidades dos fundos com o dessas empresas no período que as mesmas ainda não adotavam as normas IFRS. Desse modo, a hipótese H2 também não foi suportada, pois a rentabilidade dos fundos de investimento não apresentou maior associação com as empresas quando elas adotaram as normas IFRS.

Esses resultados sugerem que os gestores dos fundos consideram outros fatores, não necessariamente relacionados com a convergência contábil, para a escolha de seus portfólios. Observou-se também que as empresas que apresentaram maior associação com a carteira de fundos da amostra participam do índice Ibovespa desde os últimos 10 anos, o que pode indicar que os gestores dos fundos priorizam empresas mais líquidas para a composição de suas carteiras.

Especificamente, este estudo contribui com a literatura ao evidenciar uma discussão teórica sobre os benefícios da convergência contábil em termos de redução da assimetria informacional e seus efeitos na redução do risco na seleção de ativos. Evidencia-se também que os fundos de investimento, como investidores institucionais, podem ser beneficiados por relatórios contábeis de maior qualidade. Contudo, não necessariamente a adoção voluntária das IFRS foi o fator majoritariamente responsável pelas variações da rentabilidade dos fundos de investimentos da amostra, considerando-se a metodologia que foi adotada.

Uma limitação desse estudo foi a não consideração da crise econômica de 2008 como variável moderadora da rentabilidade dos fundos de investimento. Pode-se inferir que os efeitos da crise nas empresas possam ter afetado seus retornos e, consequentemente, prejudicado a análise durante esse período. Adicionalmente, as inferências realizadas neste estudo estão baseadas em indicadores de associação entre os retornos das ações das empresas 
com os retornos dos fundos de investimento, o que confere uma limitação às conclusões da pesquisa. Como sugestão para futuras pesquisas, pode-se ter um modelo estatístico mais abrangente, que envolva também as principais variáveis explicativas relacionadas à rentabilidade dos fundos de investimento, bem como um modelo de pesquisa que considere a efetiva composição das carteiras dos fundos de investimentos.

\section{Referências}

ADMATI, A. R.; ROSS, S. A. Measuring investment performance in a rational expectations equilibrium model. The Journal of Business, v. 58, n. 1, p. 1-26, 1985.

http://dx.doi.org/10.1086/296280

AMIN, G. S.; KAT, H. M. Hedge Fund Performance 1990-2000: Do the "Money Machines" Really Add Value? Journal of Financial and Quantitative Analysis, v. 38, n. 2, p. 251-274, 2003. doi: $10.2307 / 4126750$

ANBIMA - Associação Brasileira das Entidades dos Mercados Financeiro e de Capitais. Classificação de Fundos: Visão Geral e Nova Estrutura. 13/04/2015. Disponível em: http://www.anbima.com.br. Acesso em 09 out 2017.

ARMSTRONG, C. S., BARTH, M. E., JAGOLINZER, A. D., RIEDL, E. J. Market Reaction to the Adoption of IFRS in Europe. The Accounting Review, v. 85, n. 1, p. 31-61, 2010.

ASSAF NETO, A. Finanças Corporativas. 5. ed. São Paulo: Atlas, 2010.

BEUREN, I. M. Como elaborar trabalhos monográficos em Contabilidade. 3. ed. São Paulo: Atlas, 2009.

BODIE, Z.; KANE, A.; MARCUS, A. J. Investimentos. 8. ed. Trad.: Suely S. M. Cuccio. Porto Alegre: AMGH, 2010.

BM\&FBOVESPA. Índice Bovespa (Ibovespa). Disponível em:

$<$ http://www.bmfbovespa.com.br/pt_br/produtos/indices/indices-amplos/indice-ibovespaibovespa-composicao-da-carteira.htm>. Acesso em 20 abr. 2016.

BRASIL. Lei $\mathrm{n}^{\circ} 11.638$, de 28 de dezembro de 2007. Altera e revoga dispositivos da Lei $\mathrm{n}^{\circ}$ 6.404, de 15 de dezembro de 1976, e da Lei $\mathrm{n}^{\circ}$ 6.385, de 7 de dezembro de 1976, e estende às sociedades de grande porte disposições relativas à elaboração e divulgação de demonstrações financeiras. Diário Oficial [da República Federativa do Brasil], Brasília, DF, v. 134, n. 249A, 28 dez. 2007. Seção 1- Edição Extra.

CAMILO, O. C. Fluxo de Recursos e Desempenho Passado: Um Estudo sobre o Comportamento do Investidor de Fundos de Ações. 2012. Dissertação (Mestrado em Economia) Escola de Economia de São Paulo. 2012. 
CARVALHO, V. G.; SILVA, J. J.; SILVA, C. A. T. Divulgação da Informação Contábil: Influência nas Decisões de Investimentos em Ações. ReCont: Registro Contábil, v. 4, n. 2, p. 36-54, 2013.

CERVO, A. L; BERVIAN, P. A. Metodologia Científica. 4. ed. São Paulo: MAKRON Books, 1996.

CVM - Comissão de Valores Mobiliário. Instrução Normativa no 555, de 17 de dezembro de 2014. Disponível em: <http://www.cvm.gov.br >. Acesso em: 9 out. 2017.

Instrução Normativa $\mathbf{n}^{\mathbf{0}}$ 457, de 13 de julho de 2007. Disponível em:

$<$ http://www.cvm.gov.br/asp/cvmwww/atos/formatos.asp>. Acesso em: 3 maio. 2014.

DASKE, H. et al. Mandatory IFRS reporting around the world: early evidence on the economic consequences. Journal of Accounting Research, v. 46, n. 5, p. 1085-1142, 2008. doi: 10.1111/j.1475-679X.2008.00306.x

GRECCO, M. C. P., et al. Percepção dos profissionais brasileiros com relação ao processo de convergência contábil às normas internacionais. Revista Enfoque: Reflexão Contábil, v. 32, n. 3, p. 111-128, 2013. doi: 10.4025/enfoque.v32i3.17587

GROMB, D.; VAYANOS, D. Equilibrium and Welfare in Markets With Financially Constrained Arbitrageurs. Journal of Financial Economics, v. 66, n. 2-3, p. 361-407, 2002. doi: 10.1016/S0304-405X(02)00228-3

JENSEN, M. C.; MECKLING, W. H. Teoria da firma: comportamento dos administradores, custos de agência e estrutura de propriedade. Revista de Administração de Empresas, São Paulo, v. 48, n. 2, p. 87-125, 2008.

FONSECA, N.F., BRESSAN, A. A., IQUIAPAZA, R. A., GUERRA, J. P. Análise do Desempenho Recente de Fundos de Investimento no Brasil. Contabilidade Vista \& Revista, v. 18, n. 1, p. 95-116, jan./mar, 2007.

LHABITANT, F. S. On Swiss Timing and Selectivity: in the quest of Alpha. FAME Research Paper Series. Research Paper nº 27, June, 2001.

LI, H.; ZHANG, X.; ZHAO, R. Investing in Talents: Manager Characteristics and Hedge Fund Performances. Journal of Financial and Quantitative Analysis, v. 46, n. 1, p. 59-82, Feb, 2011. doi: 10.1017/S0022109010000748

LIMA, V. S. et al. Convergência Contábil e Custo de Capital Próprio: evidências em um Mercado Emergente. Encontro da ANPAD, 34. Rio de Janeiro, 25 a 29 de Setembro de 2010. Anais... Rio de Janeiro: ANPAD, 2010.

LIMA, J. B. N. A relevância da informação contábil e o processo de convergência para as normas IFRS no Brasil. 2011. Tese (Doutorado em Controladoria e Contabilidade: 
Contabilidade) - Faculdade de Economia, Administração e Contabilidade, Universidade de São Paulo, São Paulo, 2011.

LOPES, A. B.; ALENCAR, R. C. Disclosure and cost of equity capital in emerging markets: the Brazilian case. The International Journal of Accounting, v. 45, n. 4, p. 443-464, 2010. doi: 10.1016/j.intacc.2010.09.003

MALAQUIAS, R. F.; EID JR., W. Eficiência de Mercado e Desempenho de Fundos Multimercados. Revista Brasileira de Finanças, v. 11, n. 1, p. 119-142, 2013.

MARKOWITZ, H. Portfolio Selection. Journal of Finance, v. 7, n. 1, p. 77- 91, mar. 1952. doi: 10.1111/j.1540-6261.1952.tb01525.x

MARTINS, O. S.; PAULO, E. Reflexo da adoção das IFRS na análise de desempenho das companhias de capital aberto no Brasil. RCO - Revista de Contabilidade e Organizações FEA-RP/USP, v. 4, n. 9, p. 30-54, mai-ago 2010. doi: 10.11606/rco.v4i9.34766

PRADO, T. A. R. Os impactos da primeira adoção das normas IFRS nas demonstrações contábeis das companhias abertas brasileiras. 2013. Dissertação (Mestrado em Administração) - Universidade Federal de Uberlândia, Uberlândia, 2013.

RANCIARO NETO, A. Utilizando a teoria de matriz aleatória para a análise de correlações em fundos de investimentos brasileiros. ReCont: Registro Contábil, v. 3, n. 2, p. 134-148, 2012.

REZENDE, C. V.; ALMEIDA, N. S.; LEMES, S. Impacto das IFRS na assimetria de informação evidenciada no mercado de capitais brasileiro. Seminários em Administração SEMEAD, 15. 04 a 05 de Outubro de 2012. Anais... São Paulo: FEA/USP, 2012.

RIBEIRO, R. B.; CARLESSO NETO, O.; LEMES, S.; TAVARES, M. Impactos da adoção das IFRS nas empresas brasileiras pertencentes ao Índice Brasil: uma avaliação por meio dos métodos de kruskall - wallis e cluster analysis. ReCont: Registro Contábil, v. 4, n. 3, p. 71$88,2013$.

RICHARDSON, J. et al. Pesquisa Social. 3. ed. Atlas, São Paulo, 2011.

SARLO NETO, A. Relação entre a estrutura de propriedade e a informatividade dos lucros contábeis no mercado brasileiro. 2009. 189 f. Tese (Doutorado em Contabilidade) Programa de Pós-Graduação em Contabilidade, Universidade de São Paulo, São Paulo, 2009.

SCOTT, W. R. Financial Accounting Theory. 5. ed. Toronto: Pearson, 2009.

SILVA, R. F. M.; CARMONA, C. U. M.; LAGIOIA, U. C. T. A Relação entre o Risco e as Práticas de Governança Corporativa Diferenciada no Mercado Brasileiro de Ações: uma abordagem sob a égide da teoria dos portfólios de Markowitz. Revista Brasileira de Gestão de Negócios, v. 13, n. 39, p. 175-192, 2011. 
SILVA, P. C.; WEFFORT, E. F. J.; PETERS, M. R. S.; CIA, J. N. S. Impacto da Adoção das IFRS nas Empresas Brasileiras de Saneamento: a Percepção dos Profissionais do Setor.

Contabilidade Vista \& Revista, v. 21, n. 2, p. 69-94, 2010.

SILVA, R. L. M.; LOPES, A. B. Demonstrações Contábeis no Brasil após Adoção do CPC 13: reação do mercado de ações e consequências econômicas. In: Congresso USP de Controladoria e Contabilidade, 12. 26 a 27 de Julho de 2012. Anais... São Paulo: FEA/USP, 2012.

VARGA, G. Índice de Sharpe e outros Indicadores de Performance Aplicados a Fundos de Ações Brasileiros. Revista de Administração Contemporânea, v. 5, n. 3, p. 215-245, 2001. doi: $10.1590 /$ S1415-65552001000300011

* Rodrigo F. Malaquias agradece à FAPEMIG pelo apoio concedido para a realização de parte desta pesquisa (Projeto de Demanda Universal, 2014, APQ-01265-14).

* Artigo apresentado no SEMEAD (Seminários em Administração da FEA/USP) 2014. 